\title{
Editorial
}

\section{Going back to the future and why it's a good thing}

Journal of Direct, Data and Digital Marketing Practice (2013) 15, 1-2. doi:10.1057/dddmp.2013.50

Since joining the IDM 9 months ago, I've spoken at several 'digital' trade and industry shows and at many of the IDM's own member events and showpiece conferences. One of the themes I've prodded away at, aided and abetted by similarly trained and experienced digital marketing experts has been 'going back to the future' - given how direct marketing's core tenets, principles and practices lie at the heart of all good digital marketing. And that 'big data' is simply a lot of data, in different formats and silos of customer and transaction information. The trick remains, same as it ever was, to find insight into the information that can drive better or new marketing activity and performance improvement.

We could, at this point, spend an age on the huge amount of incredibly wasteful, untargeted, random, nonsensical digital real estate - advertising and email - there is. (And using email because it doesn't require cutting down trees, costly disposal or have an adverse environmental impact — I doubt you'd be terribly interested, nor will it be splashed across tabloid pages and castigated by TV programmes, such as Horizon.) However, with in-boxes jammed with unwanted missives, irritating pre-roll ads, social media interruptions from patently wrongly targeted ads and the post often reduced to bills and statements, I believe the best kind of interruptive, idea-led, relevant and timely advertising — (direct) mail — can come again to have a bigger, better, bona fide place on integrated media schedules and in multimedia campaign activities.

This notion is now given an even sharper focus for me because of the privatization of Royal Mail. For a successful float, and for operating in the private sector, it seems reasonably obvious that a combination of parcels, advertising (direct) mail and customer service will lie at the heart of RM's business growth and strategy. Indeed, these strands are already writ large on its site.

It also states that 'Royal Mail has a clear vision to be the most successful delivery company in the UK' My take on this is as follows:

- Parcels - This is being fuelled by the continued rise of e-commerce, online retailing and shopping.

- Mail - Or what's currently rather pessimistically billed as 'managing the decline of letters'. I'm choosing to believe that advertising mail can grow as a medium and flourish again as a core part of integrated marcomm campaigns. Recent multiple-source anecdotal evidence also suggests this.

- Customer focus - This demands best in class logistics, technology, adherence to own quality standards and targets.

Ahead of the sell-off, RM's marketing and sales arm, MarketReach, already does sterling work, since its inception last year, promoting the medium's uniqueness and benefits, involving itself in many aspects of the industry's infrastructure, such as councils of DMA, ourselves and so on.

Underpinning it all, as the sole provider of the still incredibly impressive 'Universal Service' in the United Kingdom, Royal Mail delivers a 6-days-a-week, one-price-goes-anywhere postal service to more than 29 million addresses across the United Kingdom. In 2012-2013, it collected and delivered more than 1 billion parcels and 14 billion addressed letters across the country. 
A breakfast with the wonderful Paddy Collister, now chief design officer at Google UK, and still proprietor of 'Directory' - the online and published resource for all the very best global direct marketing creativity - reminded me of all that is good about mail:

Flexible - It can be used to engage at every step of customer or prospect journey planning — lead generation, new product launch, relationship management or database development.

Targeted - Reaching customers at an individual level or specific groups of people who are more likely to consider buying your products or services. Multiple selection criteria and profiling potential all held in valuable database assets.

Personal - Putting your message straight into the hands of customers or prospects can only be good. Customizing based on current or past knowledge means you can build relationships and gain brand trust to drive more sales.

Tangible - With a good idea at its heart, as well as relevance, mail is impactful, immediate and durable - perfect for building brands and long-term customer relationships. If it's put aside, it's also picked up again, studied and reconsidered.

Integrated - Mail complements television, radio and newspaper ads. Driving sales after awareness is raised, things I was personally involved in testing and measuring uplift effects on when I was a client marketer at American Express back in the early to mid-eighties. Mail can also dovetail with the provision of unique codes for online use and reward customers who join in or like a product in social spaces.

Measurable - Via paper-based or online methods for sales, leads or info gathering. You can also use online discount codes, customized email addresses or phone numbers so that you customers can choose the way they get in touch with you.

Hopefully, not too much of a commercial for Royal Mail, but I do strongly believe in mail as a medium and, of course, I now have responsibility for ensuring that all DM best practices are available to each new generation of fledgling marketers.

In closing, I'm choosing to see a flotation as a reason for optimism, given that the IDM still has our peerless Diploma and Certificate in Direct and Digital Marketing and we continue to embed DM best practice in all the other digital syllabi and our growing data programmes across training and qualifications. I love the idea that direct marketing/direct mail could gain higher levels of trust and investment from more and more organizations as a core component of how they build their brands and their business in measurable ways.

The education and re-education of all the skills and techniques, which were so prevalent just a few years ago and have been gently withering away, will also need to be key components of any Royal Mail strategy going forward. 